\title{
Inhibition and kinetic studies of lignin degrading enzymes of Ganoderma boninense by naturally occurring phenolic compounds
}

\begin{abstract}
ABSTRCT
Aim

Lignolytic (lignin degrading) enzyme, from oil palm pathogen Ganoderma boninense Pat. (Syn G. orbiforme (Ryvarden)), is involved in the detoxification and the degradation of lignin in the oil palm and is the rate-limiting step in the infection process of this fungus. Active inhibition of lignin-degrading enzymes secreted by G. boninense by various naturally occurring phenolic compounds and estimation of efficiency on pathogen suppression was aimed at.

Methods and Results

In our work, 10 naturally occurring phenolic compounds were evaluated for their inhibitory potential towards the lignolytic enzymes of G. boninense. Additionally, the lignin-degrading enzymes were characterized. Most of the peholic compounds exhibited an uncompetitive inhibition towards the lignin-degrading enzymes. Benzoic acid was the superior inhibitor to the production of lignin-degrading enzymes, when compared between the 10 phenolic compounds. The inhibitory potential of the phenolic compounds towards the lignin-degrading enzymes are higher than that of the conventional metal ion inhibitor. The lignin-degrading enzymes were stable in a wide range of $\mathrm{pH}$ but were sensitive to higher temperature.
\end{abstract}

Conclusion

The study demonstrated the inhibitor potential of 10 naturally occurring phenolic compounds towards the lignin-degrading enzymes of $\mathrm{G}$. boninense with different efficacies.

Significance and Impact of the Study

The study has shed a light towards a new management strategy to control basal stem rot disease in oil palm. It serves as a replacement for the existing chemical control.

Keyword: Laccase; Lignin peroxidase; Lignin-degrading enzymes; Manganese peroxidase; Phenolic compounds; Uncompetitive inhibitor 